\title{
REPORT ON VISIT TO NIGERIA
}

\section{5th March t'o 1st May, 1952}

\section{R. G. Cochrane}

INTRODUCTION.

My recent visit in the interests of the British Empire Leprosy Relief Association to Nigeria was one of very great profit, and, thanks to the kindness of all those whom I met, I was able, I feel, to get a very fair insight into the general leprosy situation in the country.

In a tour of this nature it is impossible to give a detailed report; but in publishing this account I have endeavoured to give a general picture of the leprosy situation in Nigeria at the time of my visit. I have also tried to assess, as far as possible, the present position of sulphone therapy in Nigeria, and give some account of the results 
as I have seen them. Further, I have attempted to indicate how far I consider that leprosy in Nigeria can now be considered a controllable disease. In order to endeavour to give as clear an account of the leprosy work as I am able, I shall deal with each Region separately, but I shall not describe in detail my visits to each institution, lest this account become too long.

I left London by the B.O.A.C. Speedbird Service, Hermes, on I5th March, arriving Lagos the next day. When in Lagos I stayed with Dr. and Mrs. McLetchie. Dr. McLetchie was in the Director of Medical Services's office, and is in charge of the Department of Rural Work.

Under the new Constitution the Territory of Nigeria is divided into Eastern, Western and Northern Regions. Each Region has its own Parliament, with its own Ministers, and is, in many ways, autonomous. The Federal Capital is in Lagos, but certainly as far as the Medical Organisation is concerned, the Headquarters at Lagos have only advisory powers, and few, if any, mandatory ones. This of course means that while the Leprosy Service in Nigeria, now under Dr. T. F. Davey, O.B.E., is responsible for organising anti-leprosy work throughout the State, each Regional Director of Medical Services can decide on the way he himself proposes to organise the leprosy campaign. While this makes the task of the Centre much more difficult in one way, nevertheless it does ensure (and this is important as far as leprosy is concerned) that general principles, laid down by the Headquarters of the Leprosy Service, are modified according to local conditions.

The Eastern Region is, for reasons which will appear, much the most advanced in the matter of Leprosy Control; so one must guard against a natural tendency to draw general conclusions based on experience in that region, which may not apply in detail to other regions. The medical authorities realise this, but it is very difficult, in the matter of propaganda, to prevent statements being made which apply admirably to Eastern Nigeria, particularly to the fine work in and around Uzuakoli, but which need modifying when applied to other regions where development is less advanced.

The headquarters of the whole of the Nigeria Service is stationed at Oji River, under the direction of Dr. T. F. Davey. I may say at this point, that this Service is a model of its kind, and the work of Dr. R. H. Bland, who developed the Service up to its present state of efficiency, is worthy of all praise. Dr. Davey is, as is known, a leprologist with very great experience, and the Government is fortunate in having him to succeed Dr. Bland. There are, however, the usual difficulties which inevitably slow down the machine of progress, viz. (I) Finance, (2) Personnel. 
With regard to the financial aspect, the Colonial Development Fund set aside a sum of money for the development of the antileprosy campaign over five years. A budget was made to cover this period, but unfortunately the economic situation has not kept pace with the expansion of the Service, and what appeared to be ample provision three years ago is now found inadequate. Further, it was expected that at the end of the five year period the financing of the leprosy campaign could be undertaken through local services; but unfortunately, again owing to the world economic situation, this will not be possible. of achievement within the originally calculated period.

With regard to personnel, conditions are much more grave. At the present time there are four Area Superintendents, three of whom have medical colleagues. When it is realised that not only are these Area Superintendents responsible for institutions which accommodate, in some instances, nearly I,000 patients, but they also have to supervise segregation centres, which means the arranging of treatment and medical facilities for a population of 10,000 or more persons suffering from leprosy, the difficulty of the task is apparent. Such a situation inevitably results in the non-medical personnel of the Service having to assume a considerable burden of responsibility.

With regard to the mission institutions, the state of affairs in this respect is, if anything, more serious. As an example let us review the medical resources of the large Leprosy Colony at Itu. There were at the time of my visit between 2,000 and 3,000 patients in charge of one doctor, who also has responsibility for a general hospital. Admittedly, Dr. A. B. Macdonald, C.B.E. has so organised the work that in effect the Medical Officer undertakes his task in the way a general practitioner would approach a large practice; that is, he attends to those who report ill, and keeps the routine work running by means of a nursing sister and semi-trained staff. Nevertheless, the full potentialities of the situation cannot be developed, and under present conditions of recruitment, and the financial resources of the missions, there seems little possibility of an increase in staff.

Meanwhile the more effective sulphone therapy-particularly the more economic parent sulphone-has been introduced. One result of this is a general increase of optimism, and the hope that Dapsone (D.D.S.) will prove the answer to the problem. But this new therapeutic triumph, while undoubtedly making our task much easier of accomplishment, must, if we are to make the most of the new situation, call for strengthening of the medical staff in leprosy institutions. 
A still graver situation than before may arise if it is felt that the main task is now to increase the availability of Dapsone without a commensurate increase of other medical facilities-particularly staff-so that all active cases shall receive the personal care they deserve. It would be dangerous if a general impression were created that all that is needed is to train as many non-medical personnel (including an increasing proportion of African recruits) as may be required to ensure that there will be no difficulty in everybody getting DDS in as short a time as possible. While this is a desirable objective to pursue, let us be careful in so doing not to cause medical men to consider leprosy a speciality not worth their attention, because there is not enough specialist work of a detailed nature to undertake. If this happened conditions would deteriorate, to the permanent detriment of the work and the undoing of much of the fine achievements already attained.

It is unfortunate that, owing to the urgency of the situation and lack of sufficient personnel, there is at present no systematic and comprehensive course for medical men taking up leprosy. Leprosy Inspectors, however, receive regular courses of instruction. Dr. Davey is fully aware of the shortage of medical recruits to this Service, and has under consideration the training of medical men. I am of opinion that whenever medical men are recruited for leprosy work, they should first be given a short but intensive course of instruction in this country, so that they would have a basic knowledge before they start their duties in West Africa or elsewhere. Before being given independent responsibility officers might be sent for three months' intensive training to whatever institution the Director of Leprosy Control considered best. If possible their first posting should be to one of the better staffed institutions, where they can work with senior officers of the Leprosy Service. During this time they should be receiving further systematic instruction. Thus it will be evident to doctors that leprosy is a subject of intense medical interest, and a speciality as worthwhile entering as tuberculosis, malaria, or any other speciality. Until sufficient medical men are found with enthusiasm to take up this work, given a vision of the vast opportunities, this acute staff problem, as far as leprosy is concerned, will remain unrelieved.

I shall now briefly refer to my visits to the various areas in the country, Eastern, Western and Northern, and endeavour to give some idea of the situation in each area.

\section{EASTERN REGION. Owerri Province.}

I stayed in Lagos from March I6th to I8th. On the I8th I was able to secure a seat on a charter plane to Enugu, where I met 
Dr. Bland, and he introduced me to the Hon. Minister for Health for the Eastern Region. I stopped one night at the Headquarters of the Nigeria Leprosy Service, and proceeded the next day to Uzuakoli by kitcar.

As is known, the Uzuakoli I.eprosy Institution was started 20 years ago, and Dr. Brown, who is now Leprologist for Uganda, organised the work in those early days. Dr. T. F. Davey took over the Superintendency under the Methodist Missionary Society in 1936, and under his leadership great advances have been made. It was largely his organisation of the "Clan " system of segregation that resulted in the relatively rapid control of leprosy in the Owerri Province. The activities at Uzuakoli are divided into-

(I) The research Unit, under Dr. J. Lowe.

(2) The work and activities of the Medical Superintendent.

1. The Research Unit, under Dr. John Lowe, C.B.E., M.R.C.P.

This unit is well organised and is undertaking detailed research in all practical aspects of leprosy and its control. It would greatly strengthen the training side of the work if facilities for histopathological investigation and clinical photography were available. These facilities have not been developed owing to the serious shortage of staff. Nevertheless, despite this difficulty, the therapeutic research work has been outstanding; and Dr. Lowe is fortunate in having the services of a keen, well trained technician in Miss McNalty, for this ensures adequate organisation and control of the bacteriological examinations.

I do not need to enter into detail with reference to this unit, for its organisation and history are well known. It may be said here, as in all work in Nigeria, is shown the chief function of BELRA in the field, and the natural development of its policy. In the commencement of the work BELRA was fortunate in recruiting Dr. Lowe, who had recently retired from India. Later on the Nigeria Leprosy Service developed and the Government was able, through the Colonial Development Research Fund, to take over more responsibility for leprosy. Dr. Lowe's unit has become, as it should, an integral part of the Service. BELRA is essentially a " bridge builder," supplying money for staff and activities until such time as the Government is able to undertake the work. It can be said quite definitely that without BELRA's initial and continued help in recruiting and paying key personnel, the Nigeria Leprosy Service would have been seriously handicapped. If justification were needed for BELRA'S activities, there is ample evidence of this in the development of the Nigeria Leprosy Service.

There are two other aspects of the work which are of interest. 
In view of previous statements that there was a special variety of pale macule in Nigeria, I discussed the matter with Dr. Lowe and, from an examination of the macules seen in Uzuakoli, and biopsy study of material from elsewhere, it appears to me that the macules are not essentially different from those seen in India. There are certain basic clinical types in leprosy, and these are the same throughout the world. Confusion is caused by the relatively greater number of certain types of lesions over others in different parts of the world.

I was extremely interested to see the work on B.C.G. and lepromin in which Dr. Lowe is engaged. This work is of very important immunological significance, and should give great assistance in our concepts of leprosy prevention.

With regard to therapeutic investigation it might be mentioned that further work on the Thiosemicarbazones indicates that (I) in this part of Nigeria the serious condition of agranulocytosis may be precipitated by this therapy. (An article by Dr. Lowe on this subject appeared in the July-Oct. 1952 issue of Leprosy Review).

(2) There has been no evidence that the Thiosemicarbazones can be given less often than daily, and therefore they can only be used as a second line of therapy.

Dr. Lowe has commenced studies on the new anti-tuberculosis drug, Isonicotinic Acid Hydrazide. A recent report has appeared in the Lancet in which Dr. Lowe concludes that this drug does not appear to be as effective in leprosy as the sulphones.

\section{The work and activities of the Area Superintendent.}

Space does not allow me to discuss in detail all aspects of the work, and therefore I shall confine my report to the curative and preventive activities in connection with this large settlement.

In general discussions with Dr. Basil Nicholson, the Area Superintendent, several points of interest arose. Firstly, it should be pointed out that the segregation policy, which was inaugurated by Dr. Davey some fifteen or twenty years ago, has been so successful that the non-lepromatous cases in this area are as high as 90 per cent of the total cases, and the child rate is probably less than 5 per cent. It is interesting to note that this satisfactory state of affairs had been largely reached before sulphone therapy had been organised on a large scale, and that the segregation enforced was not absolutely rigid; therefore the chances of infection by the open case have been considerably reduced, and the epidemic of leprosy brought under control. One centre in the Bende division has actually been closed, as leprosy is now of no further significance.

This work supports three important contentions. First, as Sir 
Leonard Rogers and Dr. Muir have contended, leprosy cannot be controlled by absolute, compulsory segregation, for it causes the infective case to go into hiding. Secondly, it gives powerful evidence of the fact that partial segregation in the form of night segregation will control the disease. Thirdly, the evidence shown by this experiment supports the assertion that it is the open and infective case which is the chief public health problem, and the closed case is of much less, if any, significance. I have maintained for many years that if the open case of leprosy could be prevented from coming into night contact with healthy persons, particularly children, it should be possible to control leprosy in a community. It was very encouraging to see this achieved in the Uzuakoli area.*

The work of the Area Superintendent consists of the general medical work of the colony, the supervision and treatment of patients in the segregation units, and out-patients, as well as the over-all responsibility for the direction of leprosy work in his district. It would be tedious and unnecessary to describe in detail the multitudinous aspects of the work, and therefore I shall briefly refer to the various activities in and around the institution.

Medical. As can be expected, there is a considerable quantity of general medical work to be done. In view of the great number of cases, the organisation into "Clans," and the numerous outstations, it is only possible to undertake a limited amount of work. In this connection it may be said that materials for dressings, especially at out-stations, were very limited. In consequence of the pressure of work and a limited staff, it is only natural that in the specific treatment the authorities turn to a regimen which is easy to administer and is cheap. Hence the widespread use of oral DDS therapy. Except for areas with a relatively high lepromatous rate, the toxic manifestations have been minimal. Even under the biweekly regimen of $300-400$ mgms. there have been some cases of toxic side effects, but in this area they appear to be negligible.

The system with reference to Dapsone (DDS) treatment is similar in all the areas. The pills are distributed by a Leprosy Inspector, who notes down the dose given in a book provided for the purpose, and this book is checked from time to time. There is always the possibility of a black market in DDS pills because no system of checking can prevent this. This danger is fully realised by the authorities. Each individual Leprosy Inspector has a stock of tablets for $2-3$ weeks, and the Senior District Leprosy Inspector

\footnotetext{
- These results in the Eastern Province of Nigeria give strong support to Sir Leonard Rogers ${ }^{\circ}$ contention that leprosy would ultimately come under control if treatment were combined with adequate examination of contacts-See Cameron Prize Lecture. Edin. Med. Jl. Vol. 37 (1930) p.1.
} 
keeps a larger stock to distribute to the individual inspectors in charge of each segregation unit. In addition to the doctors, the Welfare Officers also act as a check. Supervision is as close as possible under the circumstances.

The results of sulphone therapy have been excellent, but it must be noted that many of the cases given treatment were not lepromatous, others belonged to that variety which tends to regress in the ordinary course of the disease. Nevertheless, I believe it is a wise policy to continue treatment for at least a year, so that the chances of a relapse may be lessened. In discussing this matter with Dr. Lowe and Dr. Nicholson, and seeing the type of cases which were generally discharged, it seems to me that it is fair to conclude

(I) It takes $3-5$ years for a lepromatous case to become negative and possible of discharge;

(2) As a result of sulphone therapy greater confidence has been created and, therefore, many mild or indeterminate cases have been sent away. Some of these in my experience would either not have been admitted to an institution in India, or would have been discharged earlier.

(3) Again, because of greater confidence in treatment, patients with residual macules are being discharged where, previous to sulphone therapy, they would have been kept in the institution.

These statements are not in any way prejudicial to sulphone therapy, for it has been demonstrated, and this work confirms this, that the sulphones are the most effective anti-leprosy drugs we possess and, used under adequate conditions, will render the majority of cases negative in a period of $3-5$ years. The type of cases, the organisation, and the attitude of the people are so favourable in this area, that there does not seem any reason why, within a measurable period of time, leprosy in Owerri Province should not, if it has not already done so, cease to be a serious problem. It is interesting to note that of Davey's original lepromatous cases, $98 \%$ become negative in a $4-6$ year period. It is difficult, however, to draw general conclusions on this, because not only does the epidemic of leprosy vary in different areas, but the response to sulphone therapy varies also. In this connection it may be stated that in areas such as Ogoja and Ossiomo, where leprosy is seen in the much more severe lepromatous form, the discharge rate is considerably lower.

Mention at this point should be made of relapses. It has been pointed out here, as well as elsewhere, that the case which tends to relapse is the tuberculoid case, and as yet in Nigeria there have been no 
lepromatous relapses. It would be expected that the tuberculoid cases would show an earlier relapse rate, because when the $M$. leprae in the tissues begin to show activity, there is an immediate tissue response, resulting in the clinical condition known as tuberculoid leprosy, whereas in lepromatous leprosy the tissues show no reaction to the presence of bacilli, and therefore it may be years before a relapse is detected.

\section{Segregation Centres.}

While in Uzuakoli I visited several segregation centres. These are in reality simply colonies for the segregation of active cases of leprosy. They are supervised by the Area Superintendent, or a Medical Officer, and the Leprosy Control Officers. These latter are BELRA-Toc $\mathrm{H}$ workers, now mostly taken over by the Government. The day-to-day work of the centres is under the direct control of a Leprosy Inspector and a clinic nurse. I was very impressed with this work and, considering the paucity of staff and difficulties of supervision because of the inability to visit the centres frequently enough, they were attaining their objective-the control of leprosy-remarkably well in this part of Nigeria. In these visits two conclusions were arrived at-

(I) The success of the Anti-Leprosy Campaign was due to (a) The enthusiasm of the people to see that active, and especially infective, cases were segregated, and (b) The development of segregation camps to such a high degree that in the Owerri Province the majority of cases, particularly the infective ones, were in segregation units. This splendid achievement was the result of the early work of Davey and the excellent group of medical men, headed by the officer in charge of leprosy control -in fact the work here is a model of its kind.

(2) The introduction of the sulphones was by no means the direct cause of the control of leprosy in this area. Two things took place when sulphone therapy was introduced on a wide scale(a) It gave great hope to cases of leprosy and convinced them that by this means they could get better; (b) It gave confidence to the Leprosy Service to discharge patients whom they were not previously sure could be discharged. In other words, the sulphones were introduced into an area in which leprosy, by means of segregation units, was already coming under control, and this process was thereby hastened to the great benefit of the people of the district.

I was convinced of another matter. If it had not been for the 
modification of DDS therapy by lowering the dosage, and giving the tablets twice a week instead of daily, it would have been difficult to continue oral DDS as an out-patient treatment. As I shall indicate, in the less developed areas, and where the advanced lepromatous cases are more numerous, intolerance to DDS therapy is not negligible.

From Uzuakoli I motored to the new institution in the Rivers Province at Isoba. During this journey I had the opportunity of discussing the situation with one of the BELRA workers. It was interesting to get the point of view of a layman. The work at Isoba is new and Dr. Seal has a difficult task, particularly as some of the worse affected areas lie amidst the river creeks, and are very inaccessible. The institution itself is developing into a very fine one, and will do an increasingly effective piece of work.

From Isoba I went to the large leprosy colony at Itu. It is quite impossible to give an adequate description of this hive of industry. The whole colony bore the stamp of those indefatigable workers, Dr. and Mrs. A. B. Macdonald. It was, however, very obvious that unless the staffing problems are solved the excellent work of the past years would seriously suffer.

The staff at Itu has, since my visit, been strengthened by the recruitment of another nursing sister. The future development of this colony will be followed with great interest, for I believe the colony has a great contribution to make towards the control of leprosy in Nigeria.

The part BELRA has played in the development of leprosy work in Nigeria is well illustrated by the fact that five of the nine workers at Itu at the time of my visit were BELRA workers, and it can be stated that without this help Itu could not have been maintained. The help of BELRA has been generously acknowledged.

From Itu I went to Oji River, arriving at Oji on 3rd April. While at Oji River I was able to visit several segregation units. Again I was struck by the relative mildness of the leprosy lesion, and the low incidence of lepromatous cases. It is in this area that Dapsone reatment has been used in the most extensive manner. While it is admitted that there is probably some mis-use of DDS, Dr. Garrett believes this is not serious, and that the people are learning the dangers of taking too large a dose.

Oji River Settlement has nearly r,000 patients, and the lay leprosy workers are of the greatest assistance in organising the general and welfare work. The children's work needs particular mention. Mr. and Mrs. Savory have developed this side of the work to a high degree of efficiency. They have a separate children's home, and do not allow, as is sometimes the custom, children to be 
farmed out to adults, for they contend that this practice is open to abuse and is detrimental to the full development of the child.

I had an interesting discussion with Dr. Garrett with reference to the toxicity of DDS. While it is admitted that the toxic manifestations on the previous daily regimen were relatively high, and that with DDS given twice weekly this has been very largely eliminated, yet in a small proportion of cases toxic symptoms still arise. It was interesting to note that a mental ward was under construction, and that the psychosis rate was in the neighbourhood of $0.3 \%$ of all cases treated.* It is stated that this rate is no higher than that of the normal population, and that DDS will only cause psychosis in the unstable person. In this connection it is also contended, with some justification, that even though it is admitted that an occasional death is caused as a result of toxicity from DDS, the number of patients that are saved either from death, or an even worse fate, amply justifies the use of a remedy which is practical to give and inexpensive enough to use for widespread treatment.

I was most impressed by the work at Oji River and, despite the enormous handicap of limited medical assistance, the work in this institution was of high grade, particularly the operative side.

On 7 th April I left by lorry for Ogoja. I was particularly interested in visiting this institution because of previous reports of $\mathrm{Dr}$. Barnes regarding the difficulty in the administration of DDS. On the way I visited the Emene clinic, some of the buildings of which need repair rather badly. The Leprosy Inspector stated that he had only had one case of sulphone dermatitis and one case of psychosis, and this was some months previously.

The work at Ogoja under Dr. Freeman is of a high order. This institution is fortunate in being administered by a Catholic Order, who send out trained medical workers, nurses and doctors. This means that all the Sisters in this hospital are trained.

In this institution both Sulphetrone parenterally and DDS were being used. There have been no toxic signs with Sulphetrone and, apart from some pain on injection, it seemed to be causing no trouble. On the lower dosages, and more gradual building up of the dose, the difficulty with DDS had been largely reduced. The distribution of DDS was under the direct control of the doctor or sisters. Despite this, one patient decided to store the tabletshaving pretended to swallow them-until he collected eight Ioo

- The most recent information we have indicates that this warl has now been completed, but no further cases of sulphone psychosis have arisen. In view of the large number of patients under treatment, a ward of this nature is a necessity for, as already mentioned, the psychosis rate in the African, apart from therapy, is sufficiently high to warrant expenditure on such a ward.-Editor. 
mgm. tablets, and took these in one dose. Unfortunately he did not live. This is a salutary reminder that abuse of the tablets may tend to bring serious results. In the segregation units no DDS is given to out-patients, and the dose of in-patients is only increased once a month, and if a patient misses getting his tablets three times in the month, the increase in dosage is then delayed.

I visited the segregation unit at Obuda, on the borders of the Benin Province. One very advanced leproma showed signs of toxicity-anaemia_but probably his leprosy condition had already resulted in considerable depression of the haemoglobin value in his blood. I was told of a village-Bibi-where the incidence of leprosy was considerable, and it was stated that on the border of the Cameroon country there was much leprosy. In this area the leproma rate is very high $(30 \%-40 \%)$.

On my way back to Oji River I stopped at Abba Kaliki, where there is developing, under the charge of a medical Catholic Sister, a very good institution. In this institution one case of psychosis and one severe dermatitis had been seen within the last few months.

It is obvious that the conditions in this area of Ogoja Province are far from satisfactory, owing to the paucity of staff. A certain number of cases are, however, being discharged and, because of the difficulty of personnel and the lack of funds, it seems impossible to expect more.

I left Ogoja on Saturday, I2th April, and, after visiting Abba Kaliki, arrived at Oji River about 5 p.m. the same evening. This afforded me an opportunity of discussing many points with Dr. T. F. Davey. I appreciated this chance and came to understand something of the tremendous difficulty of building up the leprosy campaign to its present stage, and of the hard task which still lies before the Leprosy Service.

I left for Ossiomo on Sunday, arriving in the evening. The situation in this part of Nigeria is much more serious than elsewhere, and seems to be more urgent even than that at Ogoja. The institution is well organised, and Dr. Lengauer, the Area Superintendent, impressed me as a careful worker who was overwhelmed with the problem in this area. The lepromatous rate was again high $(30 \%$ $40 \%$ ) and the finances available were limited; so much so that not only lepromatous cases could not be admitted, but between this year and last the number of patients had to be reduced by one hundred.

Because of the high rate of lepromatous cases Dr. Lengauer has to proceed very carefully with Dapsone treatment, and the following figures were worked out from the record cards. Of all the cases in the institution $1.2 \%$ had shown psychosis on an average of 
2.5 tablets twice a week ( $250 \mathrm{mgm}) ; 0.26 \%$ dermatitis on an average of 3 tablets a week; $0.64 \%$ hepatitis on an average of 2 tablets twice a week; and $1.5 \%$ albumen in the urine on an average of 2.2 tablets twice a week. Of all cases in the institution 3\%-5\% showed an increase of urobilin in the urine. This, Dr. Lengauer indicated, was a precursor of liver damage, and if it were not taken seriously, or if the patient received, accidentally or illicitly, further Dapsone treatment, disaster might follow.

The following symptoms had to be carefully noted. Discomfort over the hepatic area, nausea, failing appetite, or merely that patients stated they ' did not feel well.' On such complaints being made Dr. Lengauer insists that Dapsone must be stopped, for serious toxic signs may follow continuance of treatment. I saw one patient who was very seriously ill and has since died, his was the second recent death. With regard to psychosis, all recovered except one in whom mental instability appeared to be permanent, but in all probability this patient was always a potential psychotic.

Dr. Lengauer had a series of cases on aqueous sulphetrone supplied by BELRA, which had shown no serious toxic signs.

Dr. Garrett of Oji River also has had an occasional case of permanent mental upset. Admittedly, this is a price one may have to pay, and also it appears that the potential psychosis rate in the African is relatively high. I do not wish in any way to indicate that Dapsone toxicity is of necessity of serious import. It is a fact, however, that in this area even on small dosages, toxicity does occasionally occur, and this is apparently the general experience in areas where the number of advanced lepromatous cases is greater and dietetic conditions are poor. This state of affairs needs careful investigation. For these reasons it is wise to have an alternative treatment available, e.g. aqueous sulphetrone.

The tuberculosis rate seems to be relatively high, and in this institution, Dr. Lengauer says, there are at present 24 active cases.

I visited one of the outstations (Ugboha). The lepromatous rate seemed to be nearly $50 \%$. Six per cent of the cases in this area suffered from sulphone dermatitis, despite careful dosage. Only the fringe of the leprosy problem has been touched in this district, and the work seems to be in urgent need of strengthening.

The general work was of a high order and BELRA's help has proved vital, for without it, particularly in the early days, it would have been impossible to have started Ossiomo. I was greatly struck with the children's work and all help in this direction from BELRA is well worth giving.

My visit to Ossiomo concluded my tour in the South. I came away with a feeling of profound regard for those working in this 
part of Nigeria. The whole system, under the leadership first of Dr. Bland and then of Dr. Davey, is a model which could well be copied, and illustrated what can be done for leprosy. It is no mean achievement to have controlled leprosy very largely in the Owerri and Onitsha Provinces, and with the sulphones now available, combined with intelligent use of segregation, in the course of time the same results will be seen elsewhere. Success will be achieved provided the handicaps of finance and personnel are overcome.

\section{NorthrRn Nigeria.}

On my way North, I spent a weekend at Ibadan and stayed with Dr. Pottinger, the D.M.S. of the Western Region. This afforded me the opportunity to discuss matters of mutual interest, and to see the new University Medical College at Ibadan. It was most interesting to see something of the difficulties in organising a complete graduate Medical College, for many of the problems were similar to those which I had to face in Vellore in undertaking the same task.

The institutions visited in Northern Nigeria, where Dr. C. M. Ross has recently taken charge, were as follows:-

(a) The Albarka Fellowiship.

(b) Seventh Day Adventist Mission station some roo miles from Jos.

(c) Sudan United Mission at Jos.

(d) Sudan United Mission at Aloici.

(d) Sudan Interior Mission at Kano.

(f) Sudan Interior Mission at Sokoto.

(g) C.M.S.-BELRA at Zaria.

Because of the relative indifference of the population in Northern Nigeria, it will take a considerable time to bring the population to the point of accepting local segregation. This, therefore, means that institutional work in the area needs to be strengthened. I believe Dr. Ross's conditions for encouraging this work and giving grants are essentially sound. They are as follows-

I. Until such time as rural segregation units are established settlements must give priority to open cases.

2. Doctors and nursing sisters must give their full time to leprosy.

3. Children must be segregated from infective parents. The question of village segregation is much more difficult than in the South, and it will take some years before such centres are established.

It is only possible to give a brief account of my visit to the 
Northern Region institutions. The Albarka Fellowship institution holds great promise. Of the 106 patients, $30 \%$ were lepromatous, and it was felt, owing to the relatively high lepromatous rate, that first priority should be given to these cases. Dapsone had only just been started and it was therefore too early to estimate the tolerance of patients in this area to this drug.

I was deeply grateful to Dr. Ross for his great kindness in accompanying me on this tour. We proceeded to Jos and on the way visited a Seventh Day Adventist station. Dr. Hyde, who is a son of a missionary and speaks not only Hausa but also the local language, has just started a small colony. I was able to discuss principles of diagnosis and treatment with him. Again the lepromatous rate appeared to be high.

While in this area we made Jos Hill Station Hotel our headquarters and motored from there to Vom and Aloici. We visited Dr. Barnden's institution near Vom. There were Ioo cases, more than $30 \%$ of which were lepromas. I was informed that there had been a few cases of psychosis, one of whom committed suicide. I was assured that the dose of Dapsone was not more than $400 \mathrm{mgm}$ twice a week as a maximum. It is difficult to explain this occurrence, but I emphasised the need of care in stepping up the dosage of Dapsone. In addition to these cases, there was one case of dermatitis.

From Vom we proceeded to Mongu, where Dr. and Mrs. Keller of the S.U.M. are working. There were about IIo patients, of whom $50 \%$ were lepromas. Apart from the usual reactions, and one mild dermatitis, no untoward reactions appeared. Dapsone (DDS) has been in use for eight months.

We left Jos at 9 a.m. and motored to Zaria. Unfortunately, when we arrived both Dr. Smylie, of the C.M.S., and Mr. Birnbaum, the BELRA Manager, were not able to be present. Later Dr. Smylie arrived and we arranged to visit the leprosy institution at Giwa on our way to Kano. We had meanwhile a rapid tour of the Zaria institution.

Miss Hardaker the BELRA Nursing Sister was present and is an extremely hard worker. Her hospital, theatre and wards for sick patients were kept scrupulously clean.

We left Kaduna on 28.4.52 and motored to Kano, visiting as stated, Giwa on the way. While at Kano Dr. Helser made arrangements to fly us to Sokoto where we saw the Leprosy Hospital. Both Dr. Grant at Sokoto, and Dr. Dreisbach at Kano-Dr. Dreisbach was on furlough and Dr. Webber was acting for him-had excellent institutions. These institutions are equipped for first-class work and, with well-equipped laboratories and operating units, could do 
an increasingly excellent service. Every effort should be made to encourage both Dr. Grant and Dr. Dreisbach to maintain the work at a high level. It was interesting to note that both at Sokoto and at Kano aqueous sulphetrone was being used. At Kano pain on injection was mentioned as one of the difficulties. This was due, I believe, to the fact that the injections were given by the intramuscular route. I gave a number of patients their injections of sulphetrone subcutaneously, and there was little or no pain. I am of opinion that this latter route is the better, and if the solution is injected slowly the pain factor should be negligible.

At Sokoto, with Dapsone, there have occurred three cases of psychosis $(0.7 \%)$, three cases of dermatitis $(0.7 \%)$, one of hepatitis, and one death from hepatic toxemia. There has been no evidence of toxicity with parenteral sulphetrone. It is admitted that psychosis may have been in previously unstable individuals, and hepatitis, including the death, may have been in persons with already grossly damaged livers; but the interesting fact is that none of these results were seen with aqueous sulphetrone. I am not advocating the switching over to aqueous sulphetrone, but it appears that it would be well to use this as an alternative treatment.

The institution outside Kano is also first-class. The staff is greater and, in addition, there is an American missionary who is a fully trained technician. The institution would be excellent as a basic training centre. I was interested to hear that the Government of Northern Nigeria have recruited an orthopaedic surgeon, and it is hoped that in due course orthopaedic work will be possible.

I can only give the briefest of impressions of this fine work, and I feel that with institutions of this nature, and the gradual development of out-patient centres, the advance in $\mathrm{N}$. Nigeria will be as significant in the years to come as in the South. More financial aid is needed to achieve this desirable end. Doctors need help and encouragement, so that leprosy in all its aspects will be adequately studied by the enthusiastic medical staff of these institutions.

The most reasonable approach to leprosy in the North would appear to be to concentrate on central leprosy sanatoria equipped for specialised work, e.g. orthopædic surgery, admitting particularly the infective cases. In addition to this as many local segregation units as possible should be established. Out-patient clinics could be attached to these institutions, and at Government hospitals, where controlled treatment might be available.

I was deeply impressed with the growing opportunities in Northern Nigeria, and with the excellence of the work of the Missions in this area.

In closing this report I should like to express my deep and 


\section{NORTHERN NIGERIA}

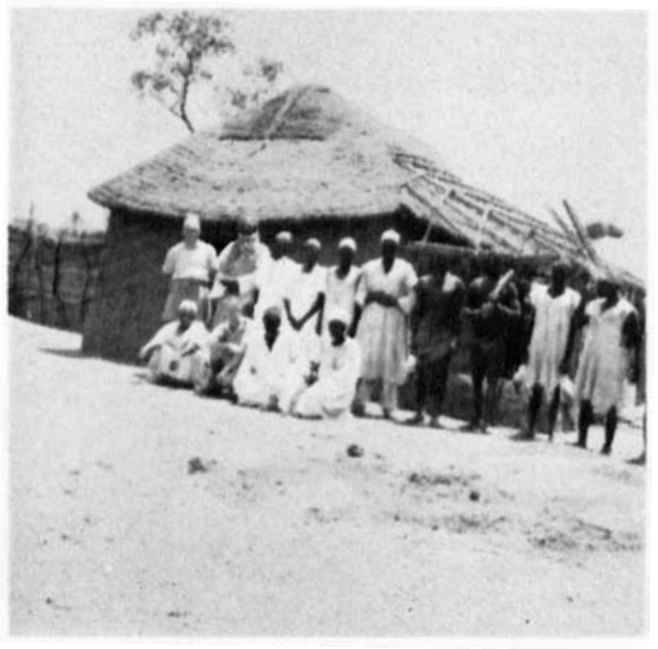

1)r. Ross with a grom of village ofticials at (iiwa, near \%aria.

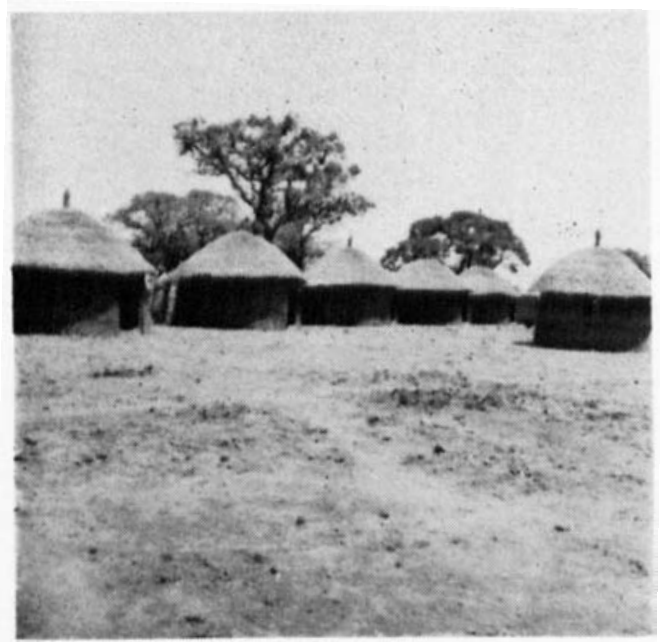

Giwa Segregation Lnit.

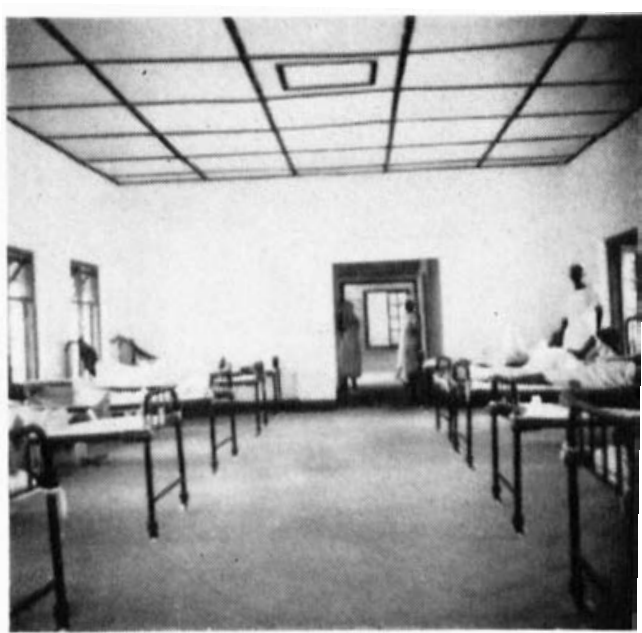

Mard at S.I.M. I.eprosy Institution, Kanc

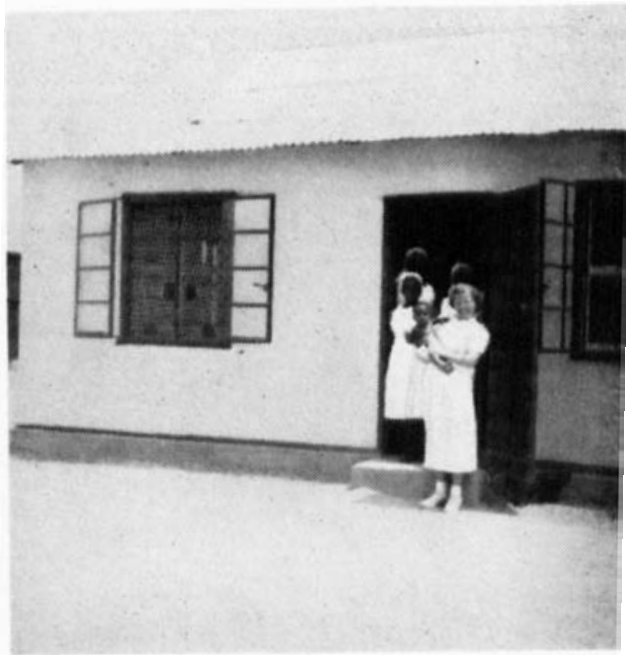

Babies' creche, I.eprosy Institution, Kans 


\section{S()WHIKN NIIIKI}

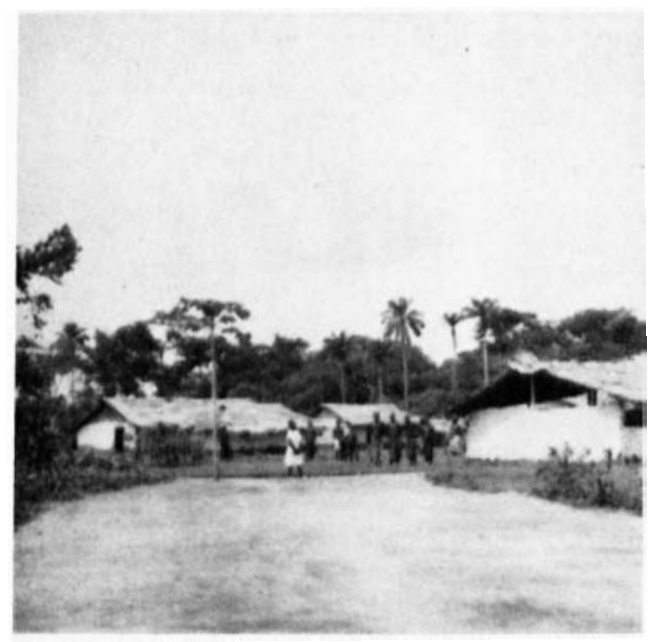

Semremation (entre near lsoba,

kivers province, s. Nigeria.

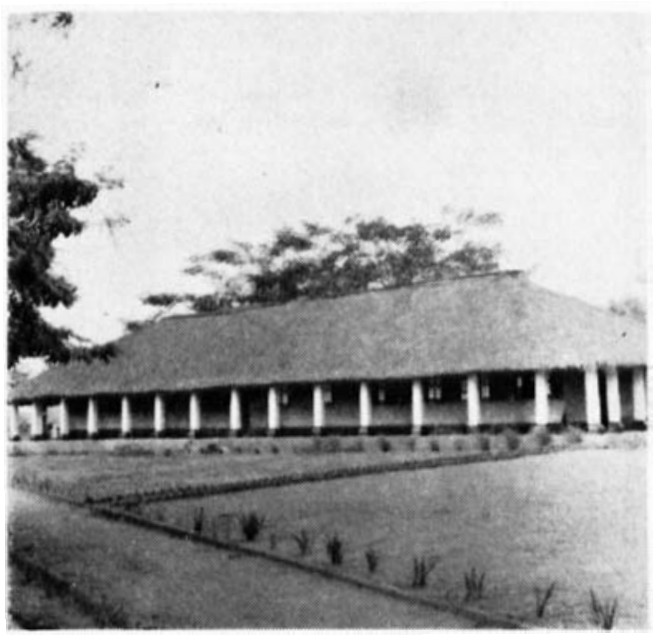

Hospital at ()goja.

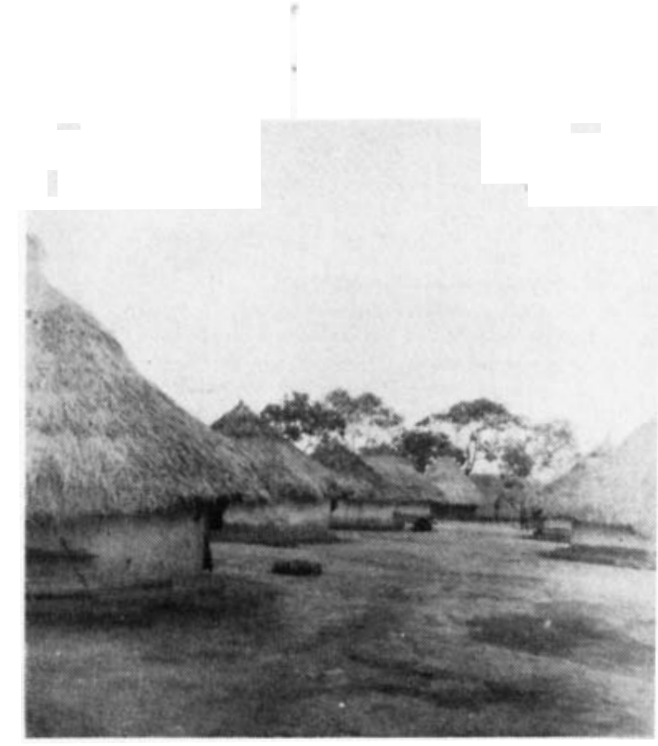

I'atients' houses at Ogoja.

Patients' houses at Itu. 
sincere thanks to all who made this tour so pleasant and profitable. I should particularly like to record my thanks for the excellent way in which I)r. I)avey and then I)r. Ross arrangeed my itinerary. The whole programme was completed without a hitch. To the Irector of Medical Services, and to I)r. Bland, and to all who guided and assisted me, I am profounclly grateful. 